\title{
Technological appropriation and socio-technical adequacy in South America: applications of digital fabrication in architecture and design
}

\section{SIGRADI2018 TECHNOPOLITICAS \\ xxii congresso da sociedade iberoamericana de gráfica digital 22th conference of the iberoamerican society of digital graphics 07|08|09|novembro|2018 iau usp | são carlos | sp br}

\author{
Rodrigo Scheeren \\ Instituto de Arquitetura e Urbanismo - USP | Brazil | rodrigoscheeren@gmail.com \\ David M. Sperling \\ Instituto de Arquitetura e Urbanismo - USP | Brazil | sperling@sc.usp.br
}

\begin{abstract}
This paper presents part of an ongoing research about the state-of-the-art of digital fabrication in South America. From case studies, it shows the characteristics of technological appropriation in architectural and design processes and artifacts, under aspects of sociotechnical adequacy, politics of fabrication and social innovation. The aim is to identify some specificities in technical, cultural and social activities, bound to local contexts and their political issues. The result is made up of six analysis categories that systematize the projects and allow a formal, functional, symbolic and political analysis, in addition to characteristics of local production.
\end{abstract}

Keywords: Digital fabrication; Contemporary architecture; Technological appropriation; Socio-technical adequacy; South America.

\section{INTRODUÇÃO}

Uma série de transformações técnicas está se convertendo em mudanças nas práticas arquitetônicas contemporâneas. A fabricação digital tornou-se um tópico de interesse no design, na arquitetura e na construção, difundido por pesquisadores e makers (Caneparo, 2014; Celani, 2012; Anderson, 2012), ao potencializar outras possibilidades de geração de protótipos, artefatos experimentais e objetos em escala real.

No caso da América do Sul, observam-se ações que envolvem desde o desenvolvimento de expertise e a adaptação de referências projetuais consolidadas em outros países, até a apropriação tecnológica e o envolvimento social dos atores com as comunidades. Os primeiros experimentos com prototipagem rápida e a compreensão acerca do potencial técnico da aplicação do maquinário digital ocorreu no início dos anos 2000, com o surgimento dos primeiros laboratórios institucionais em meados daquela década, a consolidação e difusão dos centros entre o final e o início dos anos de 2010.

Baseado em análise anterior (Sperling, Herrera, Celani, Scheeren, 2015), os aspectos econômicos, acadêmicos e culturais da implementação de laboratórios e atividades de fabricação digital em nosso contexto estão se direcionando a um terceiro estágio. Revisando e ampliando o estatuto de análise nele contemplado - com base no desenvolvimento da pesquisa -, o aspecto econômico abrange a redução do valor de aquisição e manutenção de máquinas e a ampliação de investimentos em projetos por meio de fomento governamental ou privado; o aspecto acadêmico reflete a consolidação de investigações internas às instituições e de aplicações no ensino, de agentes com conhecimento que orientam e conformam redes de compartilhamento técnico adequado; o aspecto cultural, que apesar de ainda denotar certo grau de dependência das referências externas, aponta certa diversidade na produção com especificidades locais temas, técnicas e materiais - e na propagação de um movimento faça-você-mesmo, apoiado na transmissão de informações via web e iniciativas em redes e sistemas distribuídos, como a dos Fab Labs.

Cabe investigar um aspecto complementar que permeia todos os anteriores: o social e político. Ou seja, compreender como as relações na sociedade podem ser promovidas e gerar significado ao que é produzido com as tecnologias de fabricação digital e as atividades que permeiam as suas aplicações. Interessa especificamente como a apropriação tecnológica reverte em produções correspondentes às condições dos contextos específicos de cada região, representa e reconhece fatores de diversidade e inclusão, impacta na resolução de problemas e opera na dimensão coletiva com modelos de participação e de novas formas de trabalho. A perspectiva tecnopolítica, da qual partimos para a investigação, referese à necessidade de uma abordagem complexa que relaciona as tecnologias à ciência e à economia compreendendo-as como escolhas sócio-técnicas (Laymert, 2003), promovendo práticas capazes de produzir novas formas de poder e agenciamento.

\section{OBJETIVOS}

O vasto campo de aplicações da fabricação digital está registrado em diversas referências da literatura internacional. Contudo, o foco desta literatura está na análise da produção global oriunda de países econômica e tecnologicamente desenvolvidos, localizados, principalmente, no hemisfério norte. Ainda são escassas as fontes que sistematizam uma perspectiva da produção proveniente dos laboratórios de fabricação digital na América do Sul. Logo, a intenção é formular um material que represente o que Mignolo (2003) compreende como 
uma situação, mesmo ambivalente, em que "as histórias locais estão assumindo o primeiro plano e, da mesma forma, revelando as histórias locais das quais emergem os projetos globais com seu ímpeto universal" (p. 46), explicitando algumas das relações de poder manifestas nesse cenário.

O objetivo deste trabalho é apresentar algumas propostas experimentais com vínculos sociais e políticos que representam especificidades em nossa região: modos de apropriação de projetos e tecnologias, inovação social que incorpora técnicas e culturas do fazer local, práticas situadas de envolvimento social e participação na aplicação tecnológica para a solução de problemas, expressões simbólicas que demarquem singularidades e adequações de escala em relação ao contexto no qual emergem. Além disso, oferece uma análise crítica da conjuntura em que emergem os produtos derivados de experiências que abrangem os fatores tecnológicos, técnicos e sociais da fabricação digital em nossa região.

\section{MÉTODOS}

O trabalho é um recorte da pesquisa intitulada "Centros de investigação e pesquisa em arquitetura e fabricação digital na América do Sul: estratégias de ação e o estado da arte da produção", no qual foram mapeados, recentemente, 120 laboratórios de fabricação digital na América do Sul, em suas diversas configurações.

Os métodos da pesquisa consistem na revisão de literatura (bibliográfica e sistemática), mapeamento dos centros de fabricação digitais vinculados à arquitetura e ao design na América do Sul, aplicação de questionário e a análise de estudos de caso. Diferentemente de trabalhos anteriores que descrevem o recente cenário da fabricação digital na região, a presente análise abrange os artefatos produzidos, as atividades desenvolvidas e as especificidades emergentes de cada local.

Para o artigo, selecionamos laboratórios e trabalhos relevantes para a sistematização de um quadro de referência das aplicações da fabricação digital em nosso continente, apontando desdobramentos com o aspecto político e social. A sistematização elaborada vincula os projetos aos temas da adequação sociotécnica (Dagnino, 2009) - o dispositivo tecnológico é apropriado e adaptado criticamente aos interesses políticos de grupos sociais relevantes - , da política de fabricação (Lombardero \& De Canales, 2016) - o processo gera uma estrutura de mediação para representar os habitantes, suas ações e as práticas cotidianas locais por meio da expressão material e formal - e da inovação social (Manzini, 2015) - soluções desvinculadas de modelos instituídos, atribuindo significado às ações a partir das múltiplas motivações e expectativas dos atores envolvidos.

\section{RESULTADOS}

Dos 120 laboratórios mapeados até o momento, serão destacados trabalhos realizados por: Nodo39 FabLab, TaMaCo e +ID Lab, na Argentina; FabLab Livre SP, Fab Lab SP e LAMO 3D, no Brasil; Aconcagua FabLab, gt2P, Fab Lab Santiago e FabHaus, no Chile; Tu Taller Design e FabLab Unipiloto, na Colômbia, FabLab UTPL, no Equador, e FabLab Universitario CIDI, no Paraguai. Eles representam parte do estado da arte da fabricação digital nas distintas regiões da América do Sul, através da elaboração de processos, artefatos e competências em trabalhos que promovem a adequação dos dispositivos às demandas técnicas e sociais, a inovação social ou geram uma estrutura de mediação no contexto em que atuam.

Nos casos elencados, é possível observar ações heterogêneas que envolvem desde o desenvolvimento de expertise e a adaptação de estratégias e tecnologias consolidadas em outros países para contextos com recursos reduzidos, até a apropriação tecnológica e o envolvimento social dos atores com as comunidades. Alguns importantes impactos da fabricação digital na região derivam desses dois últimos fatores, os quais envolvem: a compreensão da origem das tecnologias, suas possibilidades de uso e limitações, a construção do conhecimento acerca de sua aplicação a partir de problemas locais e a participação.

Um artefato se origina de procedimentos de análise e criação, que informam o modelo digital, e de materialização, contextualização e teste, que orientam os procedimentos de fabricação digital. Após compreendermos seus modos de adequação, os projetos selecionados foram organizados a partir das categorias de análise listadas abaixo:

1) Abrigos adaptáveis: Pabellón Furetsu (TaMaCo), Pavilhão Tornado (LAMO 3D), Habitáculo FV (Fab Lab Santiago) e Casa Abierta (Tu Taller Design).

2) Infraestruturas urbanas: Forma para calçada drenante (Fab Lab SP) e Mobiliário urbano (FabLab Livre SP).

3) Experimentos materiais: Tecnologías Expresivas bioplástico (FabLab Unipiloto) e Bio-termoplastic (FabLab UTPL).

4) Objetos (in)formados: ALADA (+ID Lab), Quantas vezes vítima (LAMO 3D) e Losing my America (gt2P).

5) Artesanías híbridas: Estructura-bastidor de tejido (Nodo39 FabLab), Dispositivo têxtil (Aconcagua FabLab), Parabrick (FabLab Universitario CIDI).

6) Dispositivos (re)codificados: Digital Analogue Machines (FabHaus) e Less $N^{\circ} 1$ Catenary Pottery Printer (gt2P).

\section{ABRIGOS ADAPTÁVEIS}

Os abrigos adaptáveis incluem estruturas espaciais que fornecem proteção para a escala humana, como suportes ou módulos de habitação. Eles representam uma série de artefatos que são recorrentes e se baseiam em iniciativas projetuais semelhantes, como as wikihouses e os pavilhões. Em sua composição geométrica, utilizam peças lisas e regulares com elementos estruturais de montagem plana, elementos regrados ou superfícies curvilíneas como base para padrões customizados com dimensões menores e adaptáveis por meio de dobras e encaixes. Desse modo, refletem exercícios direcionados à forma e ao material, com adaptações específicas às demandas funcionais e do ambiente, elementos concretos, técnicas construtivas e apropriações simbólicas do local.

O Pabellón Furetsu foi criado pelo estúdio Formosa Design para um evento itinerante na Argentina, em 2017. 
Consiste em um esqueleto estrutural leve de madeira, com peças cortadas em fresadora CNC e encaixadas na medida que formam um elemento de dupla curvatura. As pequenas peças da pele são de plástico translúcido, cortadas a laser, dobradas e encaixadas para formar módulos que são pregados entre si. O seu desenho é inspirado no esqueleto de um ouriço do mar e o resultado deriva de um protótipo anterior (Furetsu Cúpula), confeccionado com papelão reciclado de um local de conserto de televisores em um bairro próximo.

O Pavilhão Tornado é resultado de uma atividade de ensino, na qual se projetou uma intervenção temporária em espaço público utilizando superfícies regradas criadas digitalmente e construídas a partir de peças de madeira serradas, com demarcações de encaixe efetuadas com cortadora a laser. A sua proposta é a de criar um abrigo protegido e permeável, como espaço de permanência e utilização em uma área subutilizada no Parque Tecnológico UFRJ, sendo convidativo ao descanso e à sua livre apropriação como iniciativa pública.

O Habitáculo FV foi concebido como um módulo de proteção fabricado com chapas de compensado naval em camada interna e externa, conformando módulos curvados por meio de afastadores moldados com elementos estruturadores internos. Estes são coligados por presilhas metálicas aparafusadas que formam uma abóboda de curvatura simples sustentada, em cada lateral, por duas hastes metálicas usinadas. O resultado pode ser replicado com peças cortadas digitalmente e compor abrigos em locais abertos ou para situações de emergência, sendo de estrutura simplificada e rápida montagem.

A Casa Abierta foi criada como um protótipo experimental para a Feira de Design de Medellín que, diferente dos protótipos anteriores, tem um resultado mais robusto e customizável para o mercado. Com mais de $100 m^{2}$, é uma proposta sustentável composta por chapas de madeira e um sistema modular de treliças laminares em madeira, cortadas com fresadora CNC e pré-montadas. Elas exigem profissionais para a sua montagem e considera um tempo de quatro dias de fabricação e até três semanas para execução total. Assim, pode ser considerada uma solução habitacional acessível e de rápida montagem.

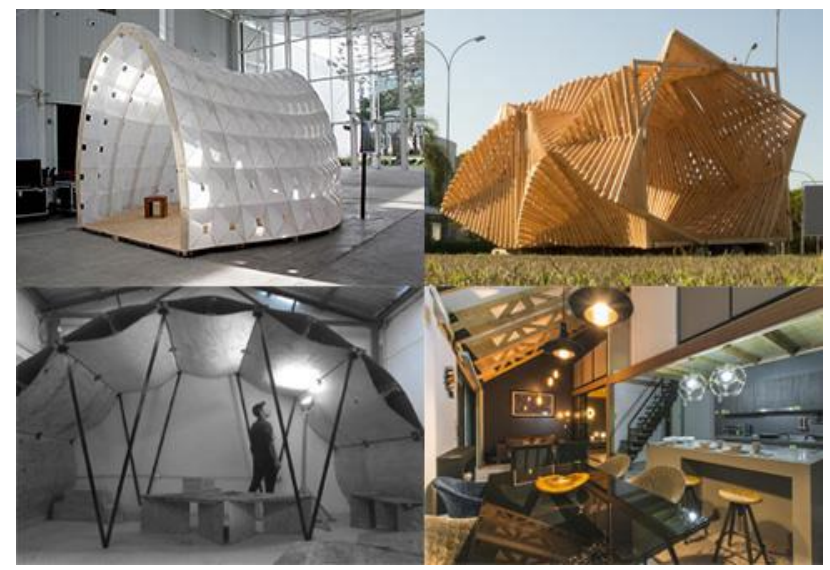

Figura 1: Furetsu (TaMaCo), Tornado (LAMO 3D), Habitáculo FV (Fab Lab Santiago) e Casa Abierta (Tu Taller Design)

\section{INFRAESTRUTURAS URBANAS}

As infraestruturas urbanas revisitam ideias de objetos tradicionais por meio de novas técnicas e estratégias construtivas, utilizando a fabricação digital como apoio para a geração de protótipos de estudo e de materialização. Os artefatos resultantes estão condicionados à pequena e média escala, em uma condição material de existência temporária ou de suporte para a consolidação de artefatos mais duradouros que utilizam técnicas complementares de materialização.

A Forma para calçada drenante é um módulo com peças de encaixe em compensado naval criado por meio de fabricação digital, utilizado como molde para a materialização de canaletas pré-fabricadas em microconcreto de alto desempenho. Os elementos em conjunto formam uma galeria subterrânea para a canalização pluvial que deve ser instalada sob as peças de calçada em concreto. O projeto tem o intuito de desenvolver a infraestrutura urbana em contextos de alta vulnerabilidade social e ambiental, recorrentes em periferias de grandes cidades e em centros urbanos sem histórico de planejamento específico para o setor no Brasil.

O Mobiliário urbano é um artefato simplificado, dos muitos protótipos que representam a retomada de um processo de interesse urbano de áreas públicas em São Paulo, para ser situado e apropriado pelas pessoas. O trabalho foi desenvolvido por alunos de uma faculdade da cidade (U. Anhembi Morumbi) que utilizam os espaços da rede de laboratórios Fab Lab Livre SP como um ambiente de investigação de novos artefatos e projetos para a cidade. Muito além do artefato, o espaço do Fab Lab oportuniza dinâmicas de interação criativa e apreensão das tecnologias em ambientes colaborativos.

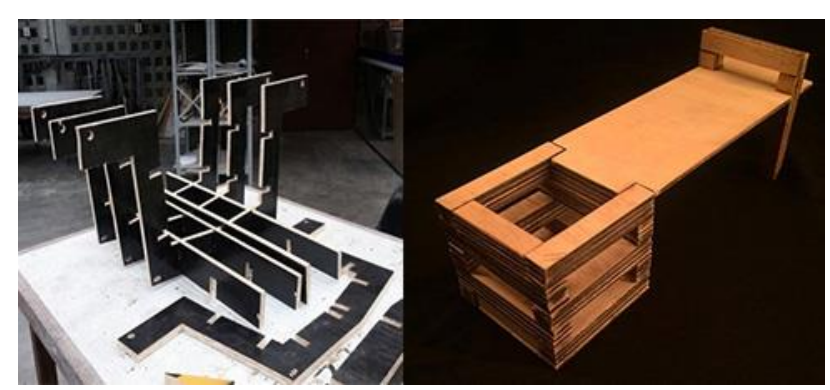

Figura 2: Forma para calçada drenante (Fab Lab SP) e Mobiliário urbano (FabLab Livre SP)

\section{EXPERIMENTOS MATERIAIS}

Os experimentos materiais incorporam investigações que alteram o foco da forma para a matéria, sem abandonar o caráter conceitual e simbólico na representação de seu processo. Os resultados são informados por ressignificações do conceito de natureza e das próprias substâncias orgânicas; tencionam uma adequação material ao ambiente no qual se inserem por meio de um amálgama com elementos biológicos e químicos.

Tecnologías Expresivas - bioplástico é um objeto experimental desenvolvido em atividade de ensino que aproxima um procedimento de tecnologia avançada ao alcance dos estudantes. A investigação material que utiliza resinas biodegradáveis e microrganismos é capaz 
de promover formas adaptáveis e irregulares, além de permitir novos modos de aplicação de materiais fabricados com manufatura aditiva e resultados que se modificam ao longo do tempo na arquitetura.

Bio-termoplastic é um elemento de proteção que pode ser utilizado em fachadas, criado para filtrar a alta intensidade de radiação UV na região equatoriana. Ele é composto por resina e acrílico termocrômico gerado a partir de modelo digital que consiste em uma estruturação formal rígida com geometria complexa de voronoi, materializada por meio de manufatura aditiva. $O$ resultado material possui efeitos particulares e pode ser adaptado em diferentes formatos.

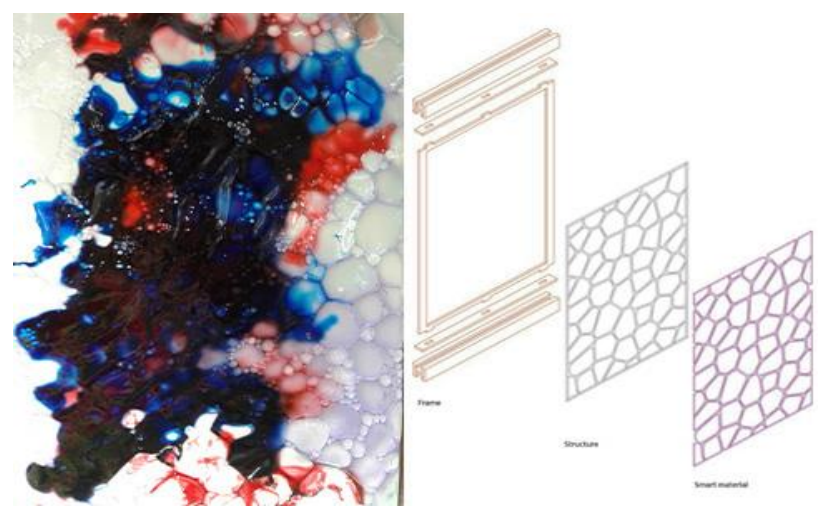

Figura 3: Tecnologías Expresivas - bioplástico (FabLab Unipiloto) e Bio-termoplastic (FabLab UTPL)

\section{OBJETOS (IN)FORMADOS}

Os objetos (in)formados investigam elementos simbólicos e formais. Fornecem matrizes generativas a partir de modelos virtuais ou até com o uso de escaneamento 3D de objetos físicos, que podem ser reestruturados e ressignificados de maneira dinâmica. Esse processo incorpora matrizes do ambiente, técnicas ou conceitos e símbolos no resultado final, elaborando geometrias complexas com características fragmentadas, tesseladas ou orgânicas.

ALADA - ou Artefacto Laminar Algorítmico DigitalAnalógico - é um artefato de experimentação morfológica desenvolvido em parceria com o Laboratório de Morfologia (FADU-UBA) e TaMaCo, que investiga interrelações entre material, forma e comportamento estrutural. Esse tipo de estudo permite gerar produtos tridimensionais com representação simbólica a partir de elementos planos unidos, sem a necessidade da montagem de peças. $O$ corte produz uma peça com resultado plástico contínuo.

Quantas vezes vítima é uma instalação desenvolvida em parceria com o grupo Gênero e Número, originária de uma reportagem que reflete a taxa de homicídios de mulheres negras no Brasil. Os dados são traduzidos em símbolos visuais por meio de geometrias na superfície plástica cortada e estruturada com elementos em madeira, todos gerados por meio de corte a laser. Dessa maneira, traduz um conjunto de números através de representação gráfica.

Losing my America é um conjunto de artefatos em que se criam peças icônicas a partir de trabalhos já desenvolvidos por artesãos locais no Chile. Os objetos originais são recodificados por meio de escaneamento tridimensional, alterações geométricas por facetamento de polígonos, e o uso de técnicas formativas e aditivas de fabricação digital. O objetivo é o de promover uma releitura de técnicas artesanais de alto valor sócio-cultural, reforçando seus laços com a economia local.
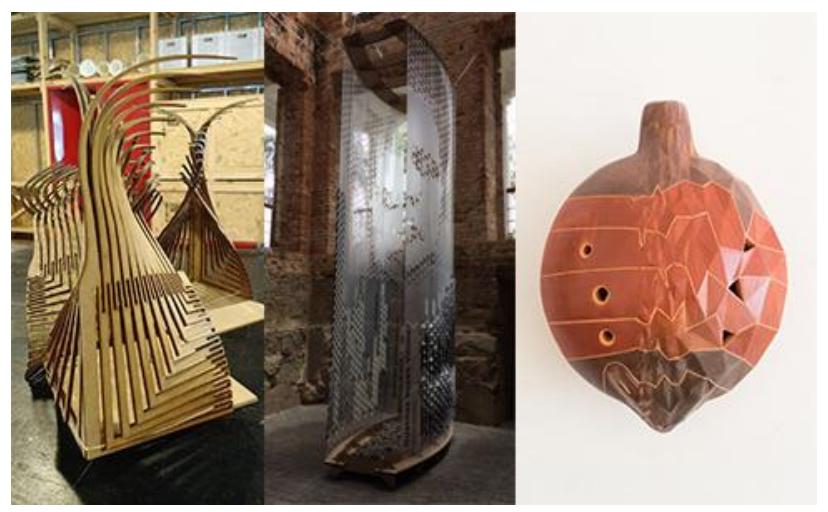

Figura 4: ALADA (+ID Lab), Quantas vezes vítima (LAMO 3D) e Losing my America (gt2P)

\section{ARTESANÍAS HÍBRIDAS}

As artesanías híbridas abrangem artefatos, instalações e estruturas que propõem aproximar procedimentos de fabricação digital e de trabalho manual. Os objetos finais são compostos de materiais e procedimentos não passíveis de serem articulados unicamente por meio de tecnologias de fabricação digital, a partir de adição ou subtração. Além disso, associam processos de revisão de técnicas artesanais estabelecidas no local por tradição cultural, que podem ser incorporadas como tema do artefato criado.

A Estructura-bastidor de tejido é uma instalação temporária criada para um evento das indústrias criativas da região de Mendoza. Ela é composta por uma estrutura de madeira utilizada para se apoiar telas e pontos com a finalidade de representar um tear de tecido, apresentando e conservando a memória do uso de técnicas têxteis antigas, como as dos indígenas da região central da Argentina.

O Dispositivo têxtil é levado ao público chileno dentro das propostas itinerantes do laboratório Aconcagua FabLab, com o intuito de renovar o interesse pelas práticas e manutenção das técnicas têxteis tradicionais da região. 0 artefato representa um pequeno tear, composto de peças em madeira e acrílico cortadas a laser, que permite a criação de tecidos regularmente trançados.

O Parabrick é um dispositivo fabricado digitalmente com peças de madeira fresadas e encaixadas, que auxilia na montagem de alvenaria de tijolos com variações de parâmetros. Ela fornece pontos para linhas-guia que estabelecem referências para a composição geométrica, podendo ser montado em qualquer canteiro de obra, facilitando o trabalho manual para a realização de composições complexas. 


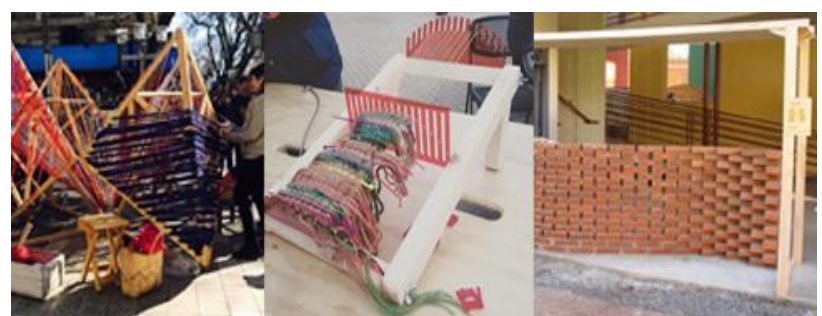

Figura 5: Estructura-bastidor de tejido (Nodo39 FabLab), Dispositivo têxtil (Aconcagua FabLab), Parabrick (FabLab Universitario CIDI)

\section{DISPOSITIVOS (RE)CODIFICADOS}

Os dispositivos (re)codificados são criados por meio de modificações tecnológicas ou inserção de elementos eletrônicos em artefatos que resultam em um funcionamento dinâmico dos mesmos. Representam um tipo de produção que está muito ligado à reflexão conceitual sobre as tecnologias. A modificação ou subversão do próprio aparelho capaz de informar ou fabricar um objeto resulta em máquinas de escala pequena ou média. Suas aplicações estão direcionadas a elementos artísticos e seus efeitos plásticos, devido a certas restrições técnicas de programação e montagem analógica e eletrônica, que são apropriadas como potencialidades na geração de protótipos nãoestandardizados.

O Digital Analogue Machines é composto por uma série de máquinas de fabricação criadas em atividade de ensino que reutilizam elementos ou dispositivos eletrônicos descartados, recorrentes no contexto importador de eletrônicos do Chile. A sua função é criar objetos (de base conceitual e artística) que associam manufatura pessoal, processos digitais e análogos, com características territoriais. Reconhece o aleatório do processo como algo positivo na indeterminação do resultado, conferindo particularidades também ao dispositivo, que se encontra entre o maquínico (analógico) e o automatizado (digital).

O Less $N^{\circ} 1$ Catenary Pottery Printer é uma máquina analógica que utiliza parâmetros controlados manualmente - sem a necessidade de computadores -, efeitos da gravidade e do comportamento físico-químico do material para criar objetos cerâmicos. A partir da montagem de uma estrutura fixa com elementos ajustáveis e flexíveis, como cordas e os tecidos que modelam as peças, os resultados são nãoestandardizados. Desse modo, atribui-se um novo significado às técnicas artesanais e à fabricação no "contexto digital" que engloba a máquina, o processo e o produto.

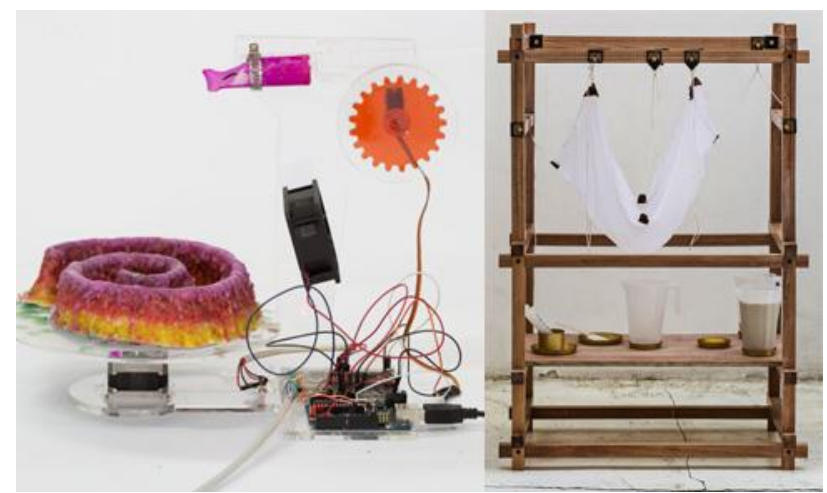

Figura 6: Digital Analogue Machines (FabHaus) e Less №1 Catenary Pottery Printer (gt2P)

\section{ANÁLISE 1: AUTONOMIA TERRITORIAL}

Os exemplos elencados refletem características muito específicas do seu meio, segundo certo grau de autonomia territorial (Deleuze, Guattari, 2005). Isto é, manifestam maior grau da emergência de interações locais específicas em relação à influência das referências projetuais estabelecidas pelo cenário de fabricação digital do exterior. Isso se conforma por um processo de agenciamento simbólico e material que preserva a heterogeneidade dos seus componentes enquanto permite a emergência de "afetos sistêmicos". A noção de autonomia territorial aqui se contrapõe ao de determinação global.

Com o maior domínio técnico e controle tecnológico em nosso contexto de restrições aquisitivas, incorporam-se conceitos, saberes convencionais e práticas analógicas para um maior grau de liberdade propositiva e de inserção do potencial das interfaces digitais e das máquinas para alcançar estratégias híbridas - em processos de desterritorialização e reterritorialização. O nível de autonomia territorial é mais representativo a medida que passamos da primeira para a sexta categoria conceitual apresentada. Ou seja, em que o procedimento de criação se desloca das revisões de paradigmas de projeto para a realização de objetos contextualizados, com resultados particulares que demarcam um caráter identitário.

\section{ANÁLISE 2: FORMAS E MATERIAIS}

Grande parte do conjunto de objetos analisados é concebida com formas retilíneas e planas, e poucos com formas curvilíneas e geometrias variadas e complexas. As escolhas facilitam o processo de fabricação e montagem, denotando um distanciamento do deslumbramento técnico da geração digital de modelos complexos, em virtude da representação do caráter funcional e simbólico do artefato. Os projetos arquitetônicos conformam uma espacialidade caracterizada pela permeabilidade e abertura, para que se compreenda a funcionalidade do objeto em sua totalidade, distintos dos objetos de design, que intensificam a plasticidade das geometrias planificadas e trianguladas geradas computacionalmente. Os materiais utilizados na fabricação são rígidos mas com pouca resistência, como a madeira e o plástico, ou superfícies plásticas e de tecidos flexíveis, incorporando a utilização de materiais de tradição local apenas em alguns artefatos fabricados.

\section{ANÁLISE 3: TÉCNICAS DE FABRICAÇÃO DIGITAL}

As técnicas de fabricação digital aplicadas aos objetos (Iwamoto, 2009), em muitos casos, são aplicadas de maneira híbrida com técnicas manuais de corte e montagem, para se alcançar os resultados formais e de combinações materiais desejadas. Além dessa estratégia, a técnica mais recorrente nos trabalhos analisados é a de seccionamento, pois favorece a obtenção de soluções construtivas partindo-se da produção de objetos em escala reduzida. Segue-se a isso o uso de técnicas aditivas, de impressão com material sintético e orgânico, e as formativas, por meio da geração de moldes para componentes e objetos de design, além de técnicas de dobradura e tesselação.

\section{ANÁLISE 4: LABORATÓRIOS, TRABALHO E SOCIEDADE}

As dinâmicas de funcionamento dos laboratórios permitem associá-los, reconhecendo as novas capacidades do 
arquiteto e a expansão da estrutura social de trabalho (Bernstein, Deamer, 2010), que influenciam nos modos de concepção e materialização dos artefatos. Há aqueles que encontram-se em espaços privados, direcionando a sua produção ao mercado e às exposições de design (gt2P e Tu Taller Design). Outros situam-se em espaços privados mas desenvolvem estratégias de funcionamento colaborativo a partir das demandas externas (Nodo39 FabLab). Alguns oferecem espaços abertos à livre participação contemplada por demandas externas plataforma maker -, com propostas de oficinas, instalações e residências (TaMaCo, Fab Lab Livre SP e Fab Lab Santiago), e os que contemplam espaços institucionais com certo nível de colaboração, regulados pela pesquisa e ensino, com algumas dinâmicas de integração com público externo (+ID Lab, Fab Lab SP, LAMO 3D, FabHaus, FabLab Unipiloto e FabLab UTPL).

É de particular interesse casos como o do Fab Lab Livre $\mathrm{SP}$, que se apresenta, em sua rede de laboratórios distribuídos em zonas de interesse na cidade, como um exemplo de plataforma para socialização, investigação e difusão do conhecimento prático, além do compartilhamento de propostas, ainda que simplórias, mas oriundas diretamente do contexto no qual está instalado. Além dele, deve-se destacar os laboratórios instalados em centros de pesquisa, que possuem uma base material e de conhecimento técnico para oferecer suporte ao desenvolvimento de demandas externas, com o potencial de integração conjunta a diversos setores da sociedade.

\section{DISCUSSÃO}

As categorias denotadas não fixam limites rígidos de interpretação, visto que vários objetos cruzam a fronteira entre mais de uma delas. A produção dos laboratórios é muito diversificada, pois é dependente das demandas internas e externas às suas atividades cotidianas - sejam elas de setores da sociedade civil, comerciais e industriais, de instituições de pesquisa e ensino ou de órgãos de governo - dificultando caracterizá-los de maneira estática. Poucos laboratórios alcançam um resultado contínuo e homogêneo, já que as aplicações da fabricação digital são, em grande parte, limitadas em quantidade e direcionadas para objetos únicos, como protótipos experimentais de pequena ou média escala.

As características assimiladas nos estudos de caso permitem configurar uma taxonomia exploratória das aplicações da fabricação digital emergentes na América do Sul, a partir das categorias de análise apresentadas. Desse modo, as propostas são organizadas através do que informa os objetos e do grau de autonomia territorial, enfatizando que tipo de especificidade é mobilizada, e não meramente por suas características formais e materiais. Os resultados apontam diferentes níveis de relevância em termos de impacto social, com exemplos que meramente tangenciam os fatores de adequação, mas denotam o crescente interesse de envolvimento com os temas.

Com base na análise dos trabalhos associados à fabricação digital, é possível designar especificidades do nosso contexto: a) o modo de tratamento adaptado das referências de projeto; b) o enfrentamento da escassez e precariedade dos meios e materiais; c) a combinação de técnicas e materiais a partir do suporte da fabricação digital; d) a revisão de conformações artesanais tradicionais sem a perda da identidade, expressos por linguagem e conceitos; e) a utilização de fatores ambientais; f) participação de agentes com distintos saberes e experiências; g) representatividade social.

Além das especificidades, emerge uma série de características associadas aos temas de interesse para a discussão. A adequação sócio-técnica, segundo Dagnino (2009), mobiliza a conscientização em relação aos usos das tecnologias, a inserção social, e as ações que tornamse vetores de orientação das agendas. A sistematização evidencia o surgimento de potencialidades de projeto que são suficientes para modificar relações de sobredeterminação das referências de produção global sobre o local, por meio de uma compreensão que articula atributos culturais, valor de uso e impacto social.

A relevância dos usos das tecnologias de fabricação digital transparece no momento em que são vinculados com problemas locais e incorporam agentes externos em tarefas de criação. Desse modo, parte-se de situações concretas para se projetar e procurar uma resolução que poderá ser materializada por meio da fabricação digital. Os modelos de colaboração ainda acontecem em sua maioria em instituições com atividades relacionadas ao ensino e pesquisa, mas há propostas de extensão em locais públicos e em contextos materialmente limitados, mas nem por isso tecnicamente restritos. A ideia de empoderamento acaba circunscrito a poucos grupos e indivíduos já estabelecidos no meio de produção.

O processo de produção que promove a inclusão de agentes locais permite a troca de informações, fomenta a dimensão criativa de soluções e adaptações a partir de um quadro que, para boa parte dos contextos, é de limitações econômicas, restrições técnicas e sociais. Essa adequação causa impacto pela socialização do conhecimento, obtendo-se ideias de fontes externas ao meio. Para tanto, é necessário estabelecer atividades que fomentem um senso de identidade e colaboração. Outro fator é a capacidade de resistência à imposição das aplicações tecnológicas e a subversão das funções e usos das máquinas disponíveis para a produção de artefatos condizentes com demandas e necessidades específicas do lugar. Isso ainda é limitado pela falta de redes de conhecimento técnico e do modelo fragmentado de iniciativas que restringe câmbios e vínculos com o local.

Desse modo, é possível desenvolver estratégias experimentais de customização de artefatos relevantes ao contexto. Estas se ligam ao efeito híbrido como potencial criativo, e à reafirmação simbólica das técnicas artesanais e aplicações da fabricação digital em ambientes de escassez. Contudo, o nível de autonomia apresentado pelos trabalhos se distancia do ideal de automação em sua produção. O que, a princípio, aparenta ser uma carência, denota a não suscetibilidade ao desejo de controle total e eliminação da intervenção humana no processo como um fator de erro para o resultado (Moe, 2010).

A política de fabricação (Lombardero, De Canales, 2016) reflete as implicações dos diferentes níveis tecnológicos, a desvinculação das variáveis de projeto advindas de um único sistema de produção, a relevância de ações coletivas a partir da livre associação individual e a 
necessidade de se questionar o status vigente. A dimensão técnica da fabricação digital, situada entre o aspecto intelectual e o prático, determina valores e interesses na cultura arquitetônica contemporânea. Nesse domínio, a ideologia - como produção social do sentido (Agrest, 2000) - que subjaz a apropriação recente das tecnologias de controle digital, tanto em cenários globais quanto locais, envolve a compreensão de discursos, práticas e contextos de emergência e difusão. A falta de uma visão crítica ante a positividade da fabricação digital pode conduzir a negligenciar ações mais importantes da arquitetura em relação à sociedade. Acreditamos que, para isso, é necessário compreendê-la por meio da abordagem do construtivismo social, que aponta o desenvolvimento tecnológico e a sua influência baseada nas escolhas dos grupos sociais, além da abertura da sua caixa-preta (Vermaas, et al, 2011, p. 89).

As tecnologias são aplicações que interferem em ações substanciais relativas às preocupações do campo humano comum ou social, nos modos de vida e na produção material, com potencial de emancipação e transformação do mundo (Lombardero, De Canales, 2016). Bonsiepe (1983), já havia apontado que é crucial abordar o tema da apropriação tecnológica em setores que não estão capacitados para produzi-la, gerando uma situação de assimetria e condição de dependência entre países centrais e países periféricos. A tecnologia torna-se uma mercadoria no momento em que não é criada uma estrutura favorável à inovação dentro de cada sociedade, pois a transferência acrítica da tecnologia pode ter efeitos questionáveis sobre as economias periféricas. Manzini (2015), por sua vez, defende que a inovação social deve direcionar a produção ao bem-estar humano, questionar a economia estabelecida, promover criações culturalmente impulsionadas e compreender a exposição às tecnologias como fator de aprendizado entre especialistas e nãoespecialistas.

Diante destas considerações, a sistematização realizada por esta pesquisa aponta ainda uma dependência da importação de tecnologias e discursos de regiões centrais, com dificuldade de assimilar todo o potencial técnico em curso, e com sérias limitações de distribuição desse fator. No momento atual, as aplicações da fabricação digital começam a receber um olhar crítico dos profissionais que compreendem as insuficiências das suas aplicações em seu contexto específico, procurando um direcionamento para algum tipo de produção que ainda não é direcionada ou absorvida pelo mercado, mas pode ser associada a algumas demandas mais urgentes das comunidades.

As propostas de produção ainda encontram uma série de limitações, principalmente para que os resultados sejam difundidos para além dos centros de pesquisa e dos profissionais envolvidos diretamente nas atividades de fabricação digital. Os processos e artefatos adquirem um fator de inovação nas situações em que surgem como instalações em espaços de acesso público, que aproximam os cidadãos de dinâmicas práticas nas quais possam interceder e modificar o meio, em produtos que reconhecem elementos culturais e técnicas do passado ou do presente, das redes de articulação e trabalho conjunto.

Com a ausência de um panorama ainda claro e amplamente discutido sobre as contribuições da fabricação digital em nosso contexto, a tendência, em um primeiro momento, foi de espelhamento de propostas do exterior, principalmente com o intuito de assimilar técnicas de controle digital. A atribuição de sentido que conferiu envergadura à disseminação da fabricação digital na América do Sul derivou de um fator de inovação propalado, mas ainda não verificado em escala, de processos e produtos customizados que seriam de grande complexidade, com diminuição do custo e do tempo de produção. Logo, percebe-se certa fetichização diante do uso das máquinas e de seu potencial.

A escolha das máquinas por parte dos agentes estudados vem seguindo critérios como o custo de aquisição, facilidade de manipulação e aprendizado, e não baseada em necessidades primárias de aplicação. Desse modo, equipamentos como impressoras 3D e cortadoras a laser foram preferidas em relação a equipamentos de porte mais robusto de produção, pautados por tecnologias disponibilizadas por grandes empresas internacionais. A aquisição de equipamentos mais robustos e com maior capacidade de produção, ainda incipiente, continua pautada pela propagação das tecnologias disponibilizadas por grandes empresas internacionais. Contudo, já apresenta casos de criação de máquinas próprias, com funções e aplicações específicas, mesmo em âmbito experimental. O uso de braços robóticos para a automação do processo de montagem ainda é uma prática distanciada, que está em estágio de assimilação técnica em poucas instituições no Chile.

A configuração dos laboratórios vem se baseando em organizações espaciais nucleadas e simplificadas, baseada na proposta da rede global Fab Lab, situadas em espaços domésticos, em pequenas oficinas digitais, em centros de ensino ou outras instituições, tanto públicas como privadas. Alguns laboratórios vêm expandindo o seu espaço de ação, como no caso da unidade móvel e itinerante do Aconcagua FabLab, que leva até o público leigo a expertise, além de atividades direcionadas à comunidade em locais externos às instituições e espaços mais acolhedores a receberem propostas de agentes externos. Além disso, já se destacam formas de organização baseadas em modelos empreendedores e de autogestão, que podem precarizar e limitar os vínculos.

Os laboratórios elencados se encontram em localização privilegiada na América do Sul: em capitais ou grandes centros urbanos, com acesso facilitado às tecnologias digitais e a uma difusão cultural em relação aos conceitos de produção digital - computação e fabricação. Desse modo, recebem não somente aportes financeiros de modo mais facilitado, mas também demandas de setores, profissionais com expertise e meios adequados para a ampla exposição e divulgação dos projetos - seja por meio físico ou virtual. Quanto mais afastados dos centros urbanos, a dinâmica de trabalho dos laboratórios tende a ser de menor intensidade, mesmo com grande potencial de assimilação de técnicas locais e associação a problemas do contexto.

Praticamente todos os projetos utilizaram processos paramétricos e generativos, demonstrando que já há um domínio técnico adequado das ferramentas digitais. A sua utilização é complementada por saberes tradicionais (gt2P, Aconcagua FabLab e FabLab Universitario CIDI); práticas de representatividade social (LAMO 3D, FabLab Livre SP); por interfaces com expressões formais e 
materiais próprias de outros campos do conhecimento (+ID Lab, FabHaus e Nodo39 FabLab); e por um compromisso com aplicações construtivas em contextos específicos (Fab Lab SP e FabLab UTPL). Alguns laboratórios estão avançando no próprio desenvolvimento de características tecnológicas do produto, como as atividades de "biofabricação", nas quais se utilizam materiais biológicos complementares à experimentação formal (TaMaCo, Fab Lab Santiago e FabLab Unipiloto).

\section{CONCLUSÃO}

A pesquisa avança sobre a compreensão do cenário atual da fabricação digital na América do Sul e propõe que as análises técnicas e tecnológicas não aconteçam desvinculadas de fatores sociais e políticos, e que evidenciem a emergência das especificidades da região nos processos e objetos produzidos. Neste estágio, situase a necessidade de divulgar as atividades e formar uma rede de colaboração mais ampla entre os laboratórios, para que possam encontrar similaridades e produzir em conjunto, estabelecendo um maior senso de identidade de grupo na região.

Parte dos laboratórios, enquanto plataformas abertas ao fazer, tem o potencial de convergir iniciativas que incorporem a participação social por meio da decisão colaborativa acerca do emprego das tecnologias desde a sua etapa inicial. Além disso, torna-se lugar privilegiado para exercitar as noções de compartilhamento e valorização da res publica. As aplicações da fabricação digital a partir das especificidades locais, pode obter um salto qualitativo no momento em que estiverem associadas a um pensamento teórico-crítico que transforme as disciplinas da arquitetura e do design em espaços deslocados da sua normatividade, em zonas de abstração imaginativa (Borden, Rendell, 2000)

Há ainda muitas oportunidades para que futuras investigações contribuam para a sistematização, narrativa e potencialização das aplicações da fabricação digital em nosso contexto.

\section{AGRADECIMENTOS}

Agradecemos a colaboração dos laboratórios citados, à Coordenação de Aperfeiçoamento de Pessoal de Nível Superior (CAPES), pela concessão da bolsa de doutorado no período de 2016 a 2017, e à Fundação de Amparo à Pesquisa do Estado de São Paulo (FAPESP) pela concessão da bolsa de doutorado a partir de 2017 (número do processo: 2017/04946-7).

\section{REFERÊNCIAS}

Agrest, D. (2000). Design versus Non-Design. In K. M. Hays (Ed.), Architecture Theory since 1968 (pp. 198-213). Cambridge, MA: MIT Press.
Anderson, C. (2012). Makers: the new industrial revolution. New York: Crown Business.

Bernstein, P., Deamer, P. (Ed.). (2010). Building (in) the Future Recasting Labor in Architecture. New York: Princeton Architectural Press.

Bonsiepe, G. (1983). A tecnologia da tecnologia. São Paulo: Edgard Blücher.

Borden, I, Rendell, J. (2000). From chamber to transformer. In I. Borden, J. Rendell (Eds). Intersections architectural histories and critical theories, (p. 3-23) London: Routledge.

Caneparo, L. (2014). Digital Fabrication in Architecture, Engineering and Construction. Dordrecht: Springer.

Celani, G. (2012). Digital Fabrication Laboratories: Pedagogy and Impacts on Architectural Education. Nexus Network Journal, 14, 469-482.

Dagnino, R. (Org.). (2009). Tecnologia social: ferramenta para construir outra sociedade. Campinas: IG/UNICAMP.

Deleuze, G., Guattari, F. (2005). A Thousand Plateaus: Capitalism and Schizophrenia. Minneapolis: University of Minnesota Press.

Iwamoto, L. (2009). Digital Fabrications: Architectural and Material Techniques. New York: Princeton.

Kurban, C., Peña-Lopez, I., Haberer., M. (2016). What is technopolitics? A conceptual scheme for understanding politics in the digital age, Building a European digital space. Proceedings of the 12th International Conference on Internet, Law \& Politics, 499-519.

Lombardero, N. Á., De Canales, F. G. (2016). Política y Fabricación Digital: una discusión en curso. Sevilla: Vibok Works.

Manzini, E. (2015). Design when everybody designs: an introduction to design for social innovation. Cambridge: MIT Press.

Mignolo, W. (2003). Histórias locais, projetos globais: colonialidade, saberes subalternos e pensamento liminar. Belo Horizonte, MG: Editora UFMG.

Moe, K. (2010). Automation takes command: the nonstandard, unautomatic history of standardization and automation in architecture. In R. Corser (Ed.). Fabricating Architecture: Selected Readings in Digital Design and Manufacturing (pp. 152-167). New York: Princeton Architectural Press.

Santos, L. G. (2003). Politizar as novas tecnologias o impacto sóciotécnico da informação digital e genética. São Paulo: Editora 34.

Sperling, D. M., Herrera, P. C., Celani, G., Scheeren, R. (2015). Fabricação digital na América do Sul: um mapeamento de linhas de ação a partir da arquitetura e urbanismo. SIGraDi 2015 - Proceedings of the 19th Congress of the Iberoamerican Society of Digital Graphics. São Paulo: Blucher, 119-125.

Vermaas, P., Kroes, P., Van de Poel, I., Franssen, M., Houkes, W. (2011). A Philosophy of Technology From Technical Artefacts to Sociotechnical Systems. San Rafael, CA: Morgan \& Claypool.

Vivanco, T. (2016). Digital | Análogo: sistemas de fabricación digital personal. Revista Diseña, 10, 152-167 